\title{
Uma perspectiva de análise da obra Série de arco de Hermeto Pascoal
}

\author{
Carlos dos Santos \\ Universidade Estadual de Campinas \\ carlosvibrafone@gmail.com
}

\begin{abstract}
Resumo: Este artigo realiza uma investigação sobre alguns processos composicionais utilizados por Hermeto Pascoal em sua obra Serie de arco, associada a uma imagética da coreografia em relação à música. Buscamos propor a ideia de que Hermeto trabalha com a perspectiva de bricolagem nesta composição. Para tanto, utilizamos recursos analíticos voltados ao delineamento de contornos musicais (STRAUS, 2013), à análise rítmica baseada em operações simétricas (SANTOS, 2018), à identificação e construção de poliacordes (PERSICHETTI, 1961; CAMARA, 2016) e à cifragem universal (CABRAL; GUIGUE, 2017).

Palavras-chave: Hermeto Pascoal, Relação Imagem-Som, Música Instrumental Brasileira.
\end{abstract}

\section{An analysis perspective of Série de arco, by Hermeto Pascoal}

Abstract: This article investigates some compositional processes used by Hermeto Pascoal in his work Serie de Arco, associated with an imagery of choreography in relation to music. We seek to propose the idea that Hermeto works with the perspective of bricolage in this composition. Therefore, we use analytical resources aimed at delineating musical contours (STRAUS, 2013), rhythmic analysis based on symmetrical operations (SANTOS, 2018), identification and construction of polychords (PERSICHETTI, 1961; CAMARA, 2016) and universal scrambling (CABRAL; GUIGUE, 2017).

Keywords: Hermeto Pascoal, Image-Sound Relation, Brazilian Instrumental Music.

\section{Introdução}

A obra Serie de arco pertence às composições de exceção no catálogo de Hermeto Pascoal, uma vez que apresenta características peculiares à sua prática hegemônica, como a ausência de um gênero popular escrito ou implícito (como baião, choro, balada), uma estrutura de leadsheet (melodia com cifra) ou uma seção de improvisação idiomática (solo instrumental sobre uma estrutura harmônica). No entanto, características do seu estilo composicional se fazem presentes nesta composição. Neste artigo, abordamos a estruturação da obra, a articulação dos elementos que embasam as características musicais

O presente artigo desenvolve o trabalho apresentado no V Encontro Internacional de Teoria e Análise Musical, EITAM5 (SANTOS, 2019, p. 291-303). 
do estilo composicional de Hermeto, bem como as razões pelas quais seria possível estabelecer uma relação entre a música e a coreografia a ela vinculadas. Para iniciarmos nossa discussão, acreditamos ser necessária uma sucinta explicação acerca da gênese da obra.

Serie de arco foi comissionada por Jovino dos Santos Neto, pianista do grupo de Hermeto Pascoal. A irmã de Jovino, Maria Luiza Santos, era atleta de ginástica rítmica e a obra musical deveria adequar-se à coreografia de uma série com o uso do arco.

No início do século $\mathrm{XX}$, a ginástica rítmica era denominada ginástica feminina moderna, tendo passado a se chamar ginástica rítmica desportiva a partir de 1974 . No entanto, ainda hoje é um esporte praticado somente por mulheres. A ginástica rítmica "prioriza os movimentos corporais leves, porém com dinamismo, harmonia e amplitude, expressando sempre a beleza e a plasticidade da ginasta..." (SARÔA, 2005, p. 29). Os exercícios são divididos em cincos séries, com os aparelhos arco, corda, fitas e maças. Embora o arco seja confeccionado com plástico rígido, com diâmetro interno entre $80 \mathrm{e}$ 90 centímetros (SARÔA, 2005, p. 34), na série com arco a ginasta precisa demonstrar versatilidade em movimentos de rolamentos, passagens, troca de mãos, rotações e pontes, além de precisar realizar, obrigatoriamente, pelo menos três saltos (LEBRE, 1993, p. 13).

Originalmente, cada série possuía obrigatoriamente um acompanhamento musical realizado por piano solo. No entanto, na década de 1980, começou a ser permitida a execução de músicas instrumentais através de fita $\mathrm{k} 7$ e essa exclusividade de repertório permaneceu até as Olimpíadas de Sidney, realizadas no ano 2000 (SARÔA, 2005, p. 2930). Nos Jogos Olímpicos de 1982, as normas determinavam que a duração da obra musical que acompanharia uma série de arco individual de ginástica rítmica deveria se estender entre 60 e 90 segundos e o início dos movimentos da coreografia não poderia exceder os oito tempos musicais iniciais da música (LEBRE, 1993, p. 9).

Não há informações disponíveis a respeito de uma pesquisa detalhada realizada por Hermeto acerca das características olímpicas acima expostas, ou mesmo se o compositor conversou com a ginasta sobre estas características. Contudo, não seria possível para qualquer compositor desconhecer as características da série específica antes de escrever 
a composição que colaboraria com sua coreografia. Jovino declara ${ }^{1}$ que houve uma observação visual de Hermeto acerca da coreografia, em uma ocasião em que ambos estiveram em um ginásio e cronometraram a coreografia para a primeira versão da composição, para piano solo (COSTA-LIMA NETO, 1999, p. 104; SANTOS NETO, [s.n.]).

Posteriormente, essa composição foi ampliada e gravada pelo grupo no LP Hermeto Pascoal e Grupo, lançado pela gravadora Som da Gente em 1982. No encarte do disco está impressa a primeira versão manuscrita da partitura para piano solo, que traz a inscrição de cinco letras (A, B, C, D, E) indicativas das mudanças de seções que acompanham os movimentos coreográficos. Todavia, não existe uma edição completa da versão arranjada para o grupo. Os únicos fragmentos remanescentes, coletados por Luiz Costa-Lima Neto (1999) junto aos instrumentistas do grupo de Hermeto, restringem-se a partes cavadas que indicam a escrita de três linhas: o piano solo com a voz inferior dobrada pelo contrabaixo; uma linha superior tocada pela flauta (eventualmente com o flautim dobrando oitava acima) e depois pelo sax soprano; e outra linha executada pela bateria. As partes de percussão, harmônio e voz foram provavelmente gravadas com as orientações do Hermeto, porém sem a presença de uma notação gráfica, e o mesmo pode ser afirmado sobre as indicações de intensidades dinâmicas e algumas articulações.

\section{A obra Série de arco}

Escrita sob a forma ternária A-B-A' (Fig. 1), a obra segue algumas das especificidades da prática esportiva da série com arco individual anteriormente descrita. Com duração aproximada de 90 segundos, os dezenove compassos da seção A (comp. 119) - consequentemente, também os da seção $\mathbf{A}^{\prime}$ - trazem a divisão realizada pelo compositor em cinco partes indicadas com letras, que em nossa análise serão grafadas minúsculas. Estas divisões seriam provavelmente indícios de momentos em que havia alterações significativas nos movimentos da coreografia. Com duração de 36 segundos, os oito compassos da seção $\mathbf{B}$ trazem a indicação da expressão ponte ${ }^{2}$, ou seja, uma seção

\footnotetext{
${ }^{1}$ Depoimento disponível na gravação ao vivo de um Show realizado no Estado do Espírito Santo, em que Jovino Santos conta a história desta composição antes de ser tocada pelo grupo (SANTOS NETO, [s.n.])

${ }^{2}$ Conjeturamos que a seção B tenha sido escrita para uma possível série de arco coletiva, podendo ser estendida até os 140 segundos regulamentares dessa modalidade.
} 
que apesar de contrastar com a primeira tem uma função de conexão entre as duas repetições da seção $\mathbf{A}$. A seção $\mathbf{A}^{\prime}$ ' consiste em uma repetição da seção $\mathbf{A}$ com inclusão do baixo elétrico e bateria - para que todos do grupo de Hermeto participassem da música de forma mais efetiva. Após a seção A' existe uma pequena coda que consiste em um comentário sonoro improvisado livremente, uma influência do Free Jazz. Dentro deste gênero, normalmente este comentário sonoro curto é intitulado start-stop.

Tabela 1 - Fatores indicativos da Forma musical e de vínculos com os movimentos esportivos.

\begin{tabular}{|c|c|c|c|}
\hline $\begin{array}{l}\text { Seções } \\
\text { (compasso) }\end{array}$ & Instrumentação & $\begin{array}{l}\text { Inscrições indicativas dos } \\
\text { movimentos esportivos }\end{array}$ & Características \\
\hline A (comp. 1-19) & Flauta/Piano & $\begin{array}{l}\mathbf{a}(\text { comp. 1-3) } \\
\mathbf{b}(\text { comp. } 4-5) \\
\mathbf{c}(\text { comp. 6-8) } \\
\text { d (comp. 9-12) } \\
\mathbf{e}(\text { comp. 13-19) }\end{array}$ & $\begin{array}{l}\text { Melodia na flauta dobrada quase } \\
\text { integralmente pela voz superior } \\
\text { do piano. Acompanhamento } \\
\text { mais lírico, quase sempre } \\
\text { arpejando. }\end{array}$ \\
\hline B (comp. 20-27) & Sax/ Tutti & Ponte & $\begin{array}{l}\text { Melodia no sax quase como um } \\
\text { solo escrito. Acompanhamento } \\
\text { com uma sonora mais densa, } \\
\text { sonoridades rugosas e } \\
\text { estridentes. Movimento } \\
\text { harmônico mais rápido. }\end{array}$ \\
\hline $\mathrm{A}^{\prime}$ (comp. 28-46) & Flauta/Tutti & $\begin{array}{l}\mathbf{a}(\text { comp. 1-3) } \\
\mathbf{b}(\text { comp. } 4-5) \\
\mathbf{c}(\text { comp. } 6-8) \\
\mathbf{d}(\text { comp. } 9-12) \\
\mathbf{e}(\text { comp. } 13-19)\end{array}$ & $\begin{array}{l}\text { Ênfase nas relações } \\
\text { contrapontísticas, com dobra do } \\
\text { contrabaixo na mão esquerda do } \\
\text { piano e inserção da linha de } \\
\text { bateria realizando polirritmias. }\end{array}$ \\
\hline Coda (comp. 47) & Tutti & & $\begin{array}{l}\text { Free Jazz } \\
\text { Start-stop }\end{array}$ \\
\hline
\end{tabular}

Fonte: Elaborado pelo autor.

Com foco na correspondência entre imagem e som, buscaremos em nossa análise sugerir quais poderiam ser os movimentos esportivos correspondentes aos elementos musicais, uma vez que 
A correspondência desejada entre música e coreografia é um indicador da relação imagem-som em Hermeto, que faz surgir em "Série de arco", uma escrita que tenta representar a agilidade, fluidez e contrastes constantes da coreografia olímpica (COSTA-LIMA NETO, 1999, p. 111).

Analisando a subdivisão $\boldsymbol{a}$ (comp. 1-3, Fig. 1) observamos uma interessante proposta de transposição imagética entre a coreografia e a música. No contorno melódico temos uma profusão de movimento contrário das vozes, formando espécies de círculos ou giros do arco na ginástica rítmica. A ideia circular é reafirmada pela ideia de proporção rítmica, quase reflexiva na proposta de acelerandos e ralentandos escritos, com alternância gradativa de velocidade. $\mathrm{O}$ sentido de continuidade decorre da ausência de pausas e da sutil oscilação nas subdivisões igualitárias.

Figura 1 - Na subdivisão $\boldsymbol{a}$, ideia de circularidade decorrente do movimento contrário no contorno das vozes condutoras, acompanhadas por acelerandos e ritardandos escritos. Pascoal, Série de arco, comp. 1-3.

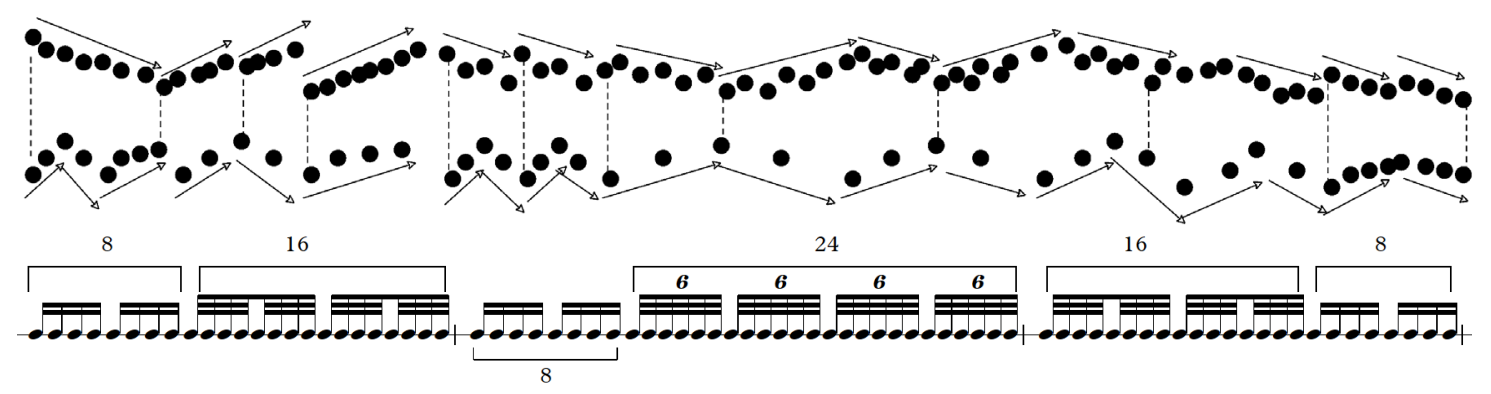

Fonte: Elaborado pelo autor.

A textura homofônica é explorada de duas maneiras neste início da obra. Nos três primeiros compassos (Fig. 1) uma linha melódica principal é executada na voz superior, acompanhada por arpejos na voz inferior. Este acompanhamento é formado quase inteiramente por $\mathrm{SEGC}^{3}<1232(1)>$, que é reflexivo. A flauta sempre dobra a voz superior do piano.

\footnotetext{
${ }^{3}$ De acordo com Straus (2013, p. 107-111), os contornos melódicos musicais (Segmentos de Contorno, SEGC; Contour Segment, CSEG) podem ser classificando numericamente de acordo com a sua disposição, atribuindo 0 à nota mais grave, 1 à segunda mais grave e assim por diante. A sequência numérica deve ser apresentada entre os símbolos $<>$.
} 
Já na subdivisão $\boldsymbol{b}$ dos compassos seguintes (Fig. 2), blocos de notas são executados homorritmicamente (BERRY, 1987, p. 192, 233), formando uma textura homofônica por acordes (KOSTKA; SANTA, 2018, p. 231). Prevalece o movimento direto no contorno das vozes condutoras (Fig. 2), relacionadas por movimento direto descendente, movimento contrário e movimento direto ascendente nas duas ocorrências finais. A densidade é ampliada através do acréscimo de notas por bloco e da ocorrência de um crescendo (ausente na partitura, mas presente na gravação). No parâmetro rítmico esta seção possui exatamente dois compassos idênticos de progressão simples de dilatação proporcional ${ }^{4}$, ou seja, dentro de um mesmo espaço temporal. Disso ocorre uma sensação de estabilidade rítmica. A flauta agora faz um desenho um pouco diferente da voz superior do piano, percorrendo um caminho de adensamento nas coleções referencias pentatônica, diatônica e cromática. Nesse contexto, entendemos que esta seção funciona como uma transição que tende ao movimento ascendente, ou seja, ao registro agudo.

Figura 2 - Na subdivisão $\boldsymbol{b}$, ideia de transição decorrente, sobretudo, da prevalência de movimento direto ascendente no contorno das vozes condutoras, da dilatação rítmica, do adensamento textural e da ampliação nas coleções referenciais. Pascoal, Série de arco, comp. 4-5.
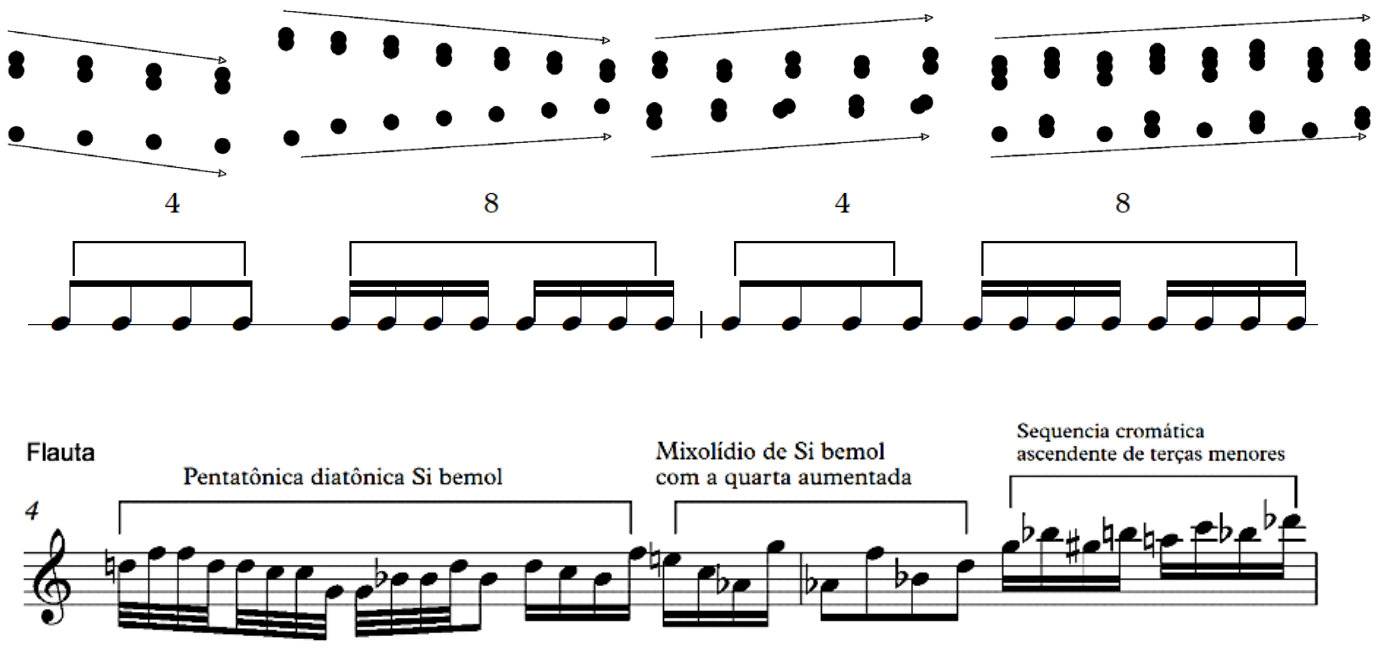

Fonte: Elaborado pelo autor.

\footnotetext{
${ }^{4}$ Importante salientar que compreendemos como dilatação e não necessariamente como aumentação ou diminuição, pelo fato deste tipo de fenômeno ser passível de observação em qualquer um dos sentidos (SANTOS, 2018, p. 62-63).
} 
Na subdivisão $\boldsymbol{c}$ (Fig. 3), um jogo de complementariedade rítmica em que uma voz toca nos espaços vazios da outra voz provoca quatro movimentos ascendentes seguidos de três descendentes, com um movimento direcional ascendente mais amplo ao final.

Figura 3 - Na subdivisão $c$, complementaridade rítmica. Pascoal, Série de arco, comp. 6-8.

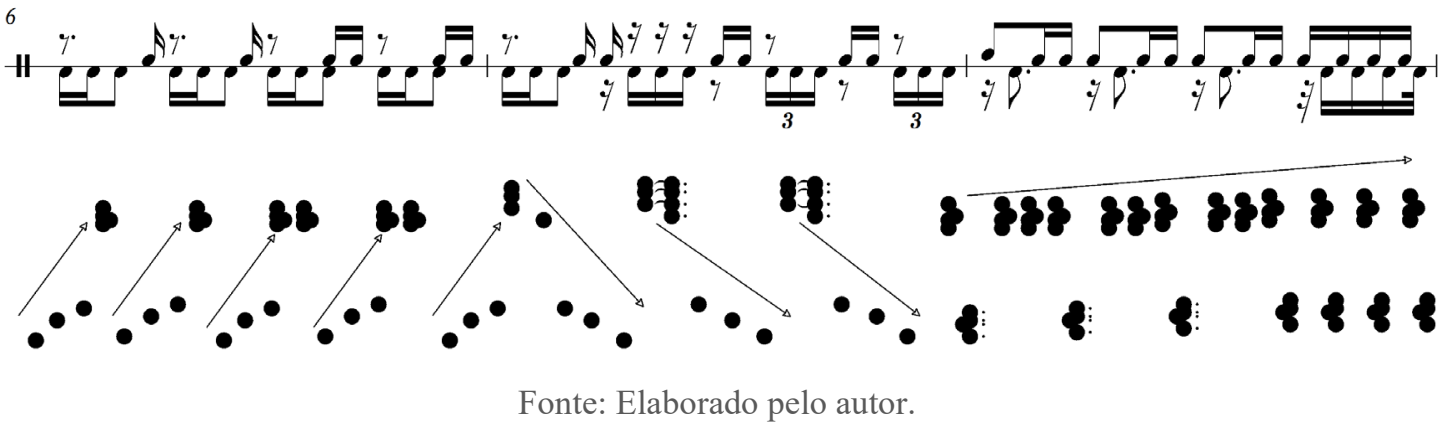

A linha de flauta foi escrita após a concepção original para piano. Entendemos aqui que existe uma escrita que se assemelha à improvisação idiomática de música brasileira orientada jazzisticamente. Isto é confirmado no próximo compasso (Fig. 4), equivalente ao início da subdivisão $c$.

Figura 4 - No início da subdivisão $c$, escrita com orientação idiomática de música brasileira orientada jazzisticamente.

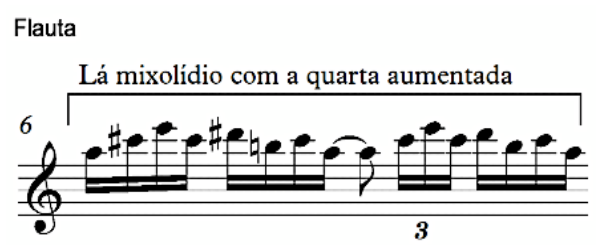

Fonte: Pascoal, Série de arco, comp. 6, com intervenção analítica do autor do presente trabalho.

Essa "abertura de vozes" entre a flauta e o piano é um procedimento comum na música popular brasileira. Quando utilizada no modo mixolídio com quarta aumentada e ressaltando intervalos de terça, é comumente associada a uma ambientação musical do nordeste brasileiro como um todo. Porém, por ter sido escrita por Hermeto com o objetivo 
de ampliar a composição para execução por seu grupo instrumental, esta linha da flauta pouco tem relação com a coreografia. Mesmo assim, é possível observar uma ideia coreográfica no final da linha da flauta nesta subdivisão $c$ (Fig. 5). As pequenas ondas presentes neste contorno da linha de flauta remetem a movimentos curtos de rotação do arco da coreografia.

Figura 5 - No final da subdivisão $c$, remissão a movimentos ondulatórios curtos. Pascoal, Série de arco, comp. 8.

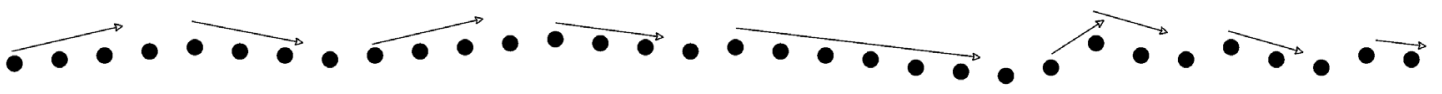

Fonte: Elaborado pelo autor.

Hermeto Pascoal normalmente utiliza-se de um sistema de notação harmônica conhecido por cifragem universal, que consiste em identificar através de letras, traços e números "estruturas verticais polifonicamente expandidas constituídas pela fusão de dois ou mais acordes diferentes executados simultaneamente" (CABRAL; GUIGUE, 2017, p. 1). Este procedimento é assemelhado ao conceito de poliacorde, a combinação de dois ou mais acordes (geralmente tríades ou acordes de sétima, sendo possível a combinação de outros tipos de acordes), formando uma sonoridade mais complexa em que a identidade de ambos é mantida (KOSTKA; SANTA, 2018, p. 59). No entanto, Fábio Adour de Camara (2014, p. 477) relata que, muitas vezes no repertório popular, o poliacorde pode ser utilizado somente como uma simplificação gráfica da cifra, para facilitar o entendimento de tríades que possuem muitas notas adicionais. Jovino (apud COSTALIMA NETO, 1999, p. 7), que trabalhou muitos anos com Hermeto, levanta a hipótese de que a utilização de tríades sobrepostas possa ter vindo do contato de Hermeto com a sanfona de oito baixos ou pé-de-bode na infância, quando a ouvia sendo tocada por seu pai. Essa sanfona diatônica de oito baixos foi tocada também por Hermeto até os 11 anos de idade, quando ele foi presenteado com uma sanfona de 32 baixos (SILVA, 2009, p. 8). As sanfonas ou acordeons possuem um sistema de botões em que o acionamento de cada um deles resulta na execução de um acorde, normalmente uma tríade maior, menor e diminuta. Sendo assim, os acordes estendidos para além da quinta requerem combinações 
dessas tríades. Talvez possamos dizer que Hermeto, ao longo de sua trajetória, ampliou este sistema de combinações triádicas para gerar a sua linguagem harmônica.

Na obra Série de arco, Hermeto não se utiliza desta notação em forma de cifras. No entanto, podemos notar a ideia de sobreposição de tríades persiste ao longo de toda a composição. Nas subdivisões $\boldsymbol{a}$ e $\boldsymbol{b}$ (Fig. 6), uma das principais características harmônicas é a presença de acordes mais consonantes, com priorização de quintas e quartas, nos dois primeiros tempos de cada compasso. Nos dois últimos tempos desses mesmos compassos, temos acordes mais dissonantes, que priorizam segundas menores e maiores ${ }^{5}$. No final do quarto compasso, a nota lá bemol que transforma o acorde em diminuto funciona como antecipação do acorde do próximo compasso (inclusive, esta nota encontra-se somente na parte de flauta). Notamos que, na subdivisão $\boldsymbol{b}$, temos uma sequência de movimento descendente (comp. 4) e outra ascendente (comp. 5). Essa espécie de espelhamento pode motivar um movimento de maior relaxamento, suscitando uma curvatura do corpo da ginasta para a frente ou em direção ao solo do tablado, enquanto o próximo compasso harmonicamente tende a posição mais esticada em pé ou com um salto no ar.

Figura 6 - Nas subdivisões $\boldsymbol{a}$ e $\boldsymbol{b}$, compassos iniciados por acordes mais consonantes e finalizados por acordes mais dissonantes.
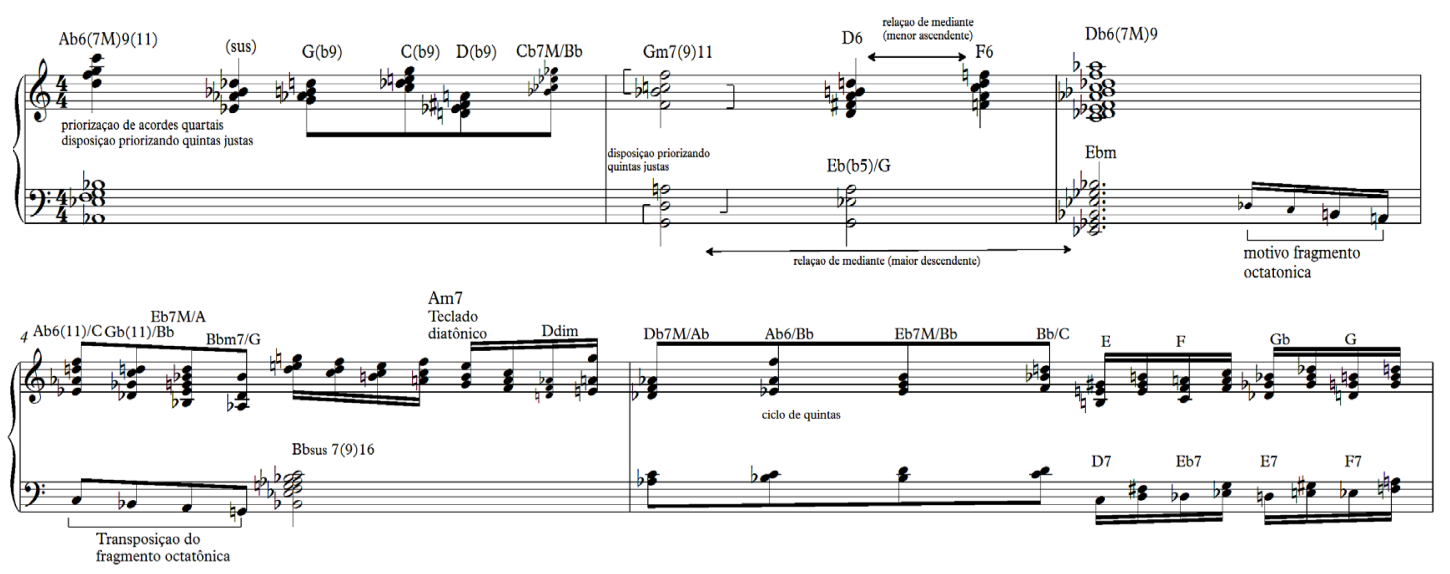

Fonte: Pascoal, Série de arco, comp. 1-5, com intervenção analítica do autor do presente trabalho.

\footnotetext{
${ }^{5} \mathrm{Na}$ última colcheia do primeiro compasso talvez exista um "erro", provavelmente resultante da escrita instantânea de Hermeto. Seguindo-se pela coerência da sequencia harmônica, esse acorde seria um Dó bemol com a nona menor [Cb (b9)], ou seja, no lugar da nota si bemol teríamos um Ré dobrado bemol.
} 
A Tabela 2 traz a distribuição das alturas nas três primeiras subdivisões, equivalentes aos oito compassos iniciais da composição. Temos a quantidade de notas utilizadas em cada compasso e abaixo as notas que eventualmente não foram utilizadas para completar o total cromático.

Tabela 2 - Distribuição das alturas do total cromático nas três primeiras subdivisões da seção A.

\begin{tabular}{lllllllll}
\hline Compassos & Comp. 1 & Comp. 2 & Comp. 3 & Comp. 4 & Comp. 5 & Comp. 6 & Comp. 7 & Comp. 8 \\
\hline Qtd. notas & 12 & 9 & 10 & 12 & 12 & 11 & 12 & 12 \\
Notas ausentes & & C\#-E-G\# & D-E & & & F\# & & \\
\hline
\end{tabular}

Fonte: Elaborado pelo autor.

$\mathrm{Na}$ subdivisão $\boldsymbol{d}$ (Fig. 7) temos uma estrutura 1221 por compasso, ou seja, o primeiro compasso do ponto de vista de contorno e material é desenvolvido no quarto compasso, enquanto os dois compassos centrais são exatamente idênticos. $\mathrm{Na}$ linha inferior da estrutura 1, temos um movimento mais dinâmico do ponto de vista de contorno, enquanto a linha superior é mais estática. Na estrutura 2, existe uma inversão de movimentos - a linha superior descreve um grande movimento ascendente e a inferior é mais estática. Dentre todas as cinco subdivisões da obra, essa é a que tem mais repetições de acordes, representadas pelos colchetes na Figura 7. A estrutura 1 possivelmente corresponda a um dos saltos da ginasta já que o compositor utiliza pela primeira vez a sincopa que provoca um deslocamento do tempo. A presença dos clusters em trinados na estrutura 2 geram uma sonoridade bastante rugosa, que talvez tenha sido representado com um momento mais complexo ou confuso nos movimentos da coreografia.

O primeiro compasso da subdivisão $\boldsymbol{d}$ (comp. 9, na Fig. 8) possui um único conjunto de alturas (5-31), provavelmente obtido pela sobreposição de dois acordes, um menor e outro diminuto - por exemplo, Dó menor com dó diminuto. Este conjunto é resultante da sobreposição da linha superior do piano com a linha de flauta. 
Figura 7 - Na subdivisão $\boldsymbol{d}$, ideia de circularidade decorrente do movimento contrário no contorno das vozes condutoras, acompanhadas por acelerandos e ritardandos escritos. Pascoal, Série de arco, comp. 9-12.
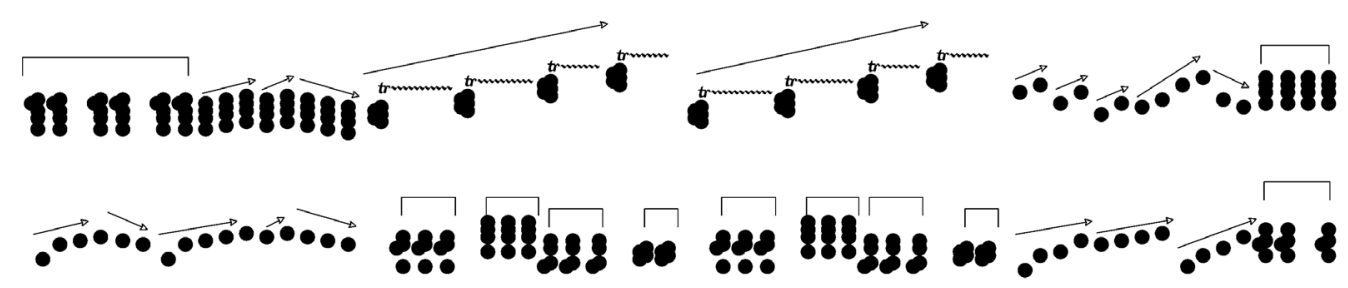

Fonte: Elaborado pelo autor.

Figura 8 - No início da subdivisão $\boldsymbol{d}$, sobreposição de duas tríades, menor e diminuta, invertidas e com a mesma fundamental Dó. Pascoal, Série de arco, comp. 9, redução.

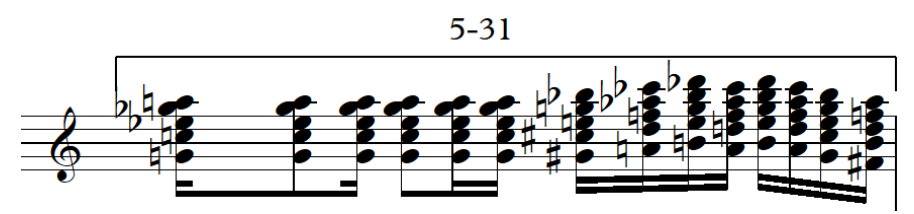

Fonte: Elaborado pelo autor.

A subdivisão $\boldsymbol{e}$ é a maior dentre as cinco e equivale à seção final da coreografia solo original. Sua estrutura é mais evidente no substrato rítmico, que consiste na alternância entre compassos com tercinas de semicolcheias e compassos com fusas. A redução rítmica (Fig. 9) traz a divise no compasso 14, com a sobreposição de duas camadas rítmicas contínuas. No entanto, as fusas ocorrem nas linhas de flauta e flautim, ou seja, não estariam na versão original para piano solo.

Figura 9 - Na subdivisão $\boldsymbol{e}$, substrato rítmico indicativos de continuidade. Pascoal, Série de arco, comp. 13-19.

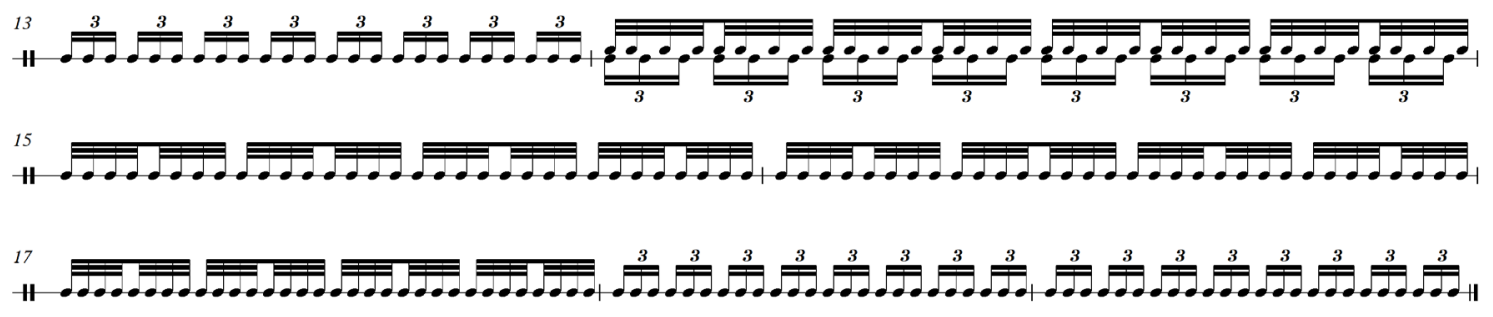

Fonte: Elaborado pelo autor. 
Harmonicamente, o compositor continua trabalhando com poliacordes e sequências harmônicas direcionais, por vezes ambíguos. Por exemplo, nos compassos 13 e 14 (Fig. 11) temos ao piano uma sobreposição que envolve uma sequência de tríades maiores em movimento ascendente sobre um acorde pedal de Dó\# maior com sétima maior e nona e este acorde sem terça pode ser interpretado também como sendo de Sol\# maior com a quarta no baixo.

Figura 10 - Na subdivisão $\boldsymbol{e}$, sucessão harmônica e ambiguidade. Pascoal, Série de arco, comp. 13-14.

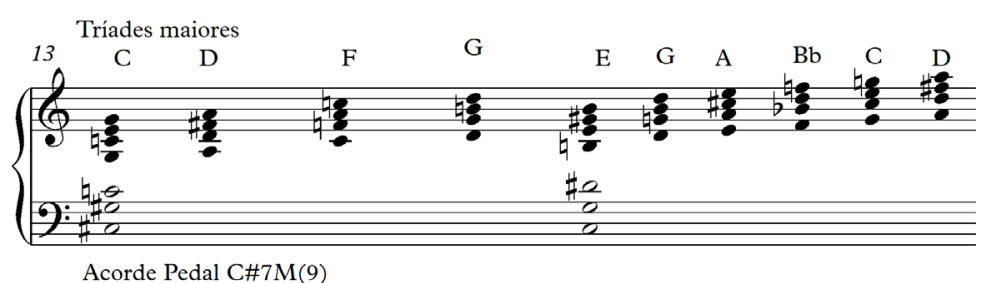

Acorde Pedal C\#7M(9)

Fonte: Elaborado pelo autor.

No compasso 14 da versão arranjada para grupo (Fig. 11), Hermeto introduz uma sequência melódica descendente na flauta, formada pela transposição de um grupo de quatro alturas (conjunto 4-9). Este padrão com o SEGC <3421>, da forma como é proposto, é simétrico com duas resoluções de sensíveis separadas por um trítono - por exemplo, no primeiro grupo a nota Ré\# resolve no Mi e a nota Sib resolve no Lá. Este padrão é transposto sempre uma segunda maior abaixo, o que gera escalas hexatônicas simétricas. Esse movimento alude ao movimento do arco rodando no braço da ginasta, desde a parte alta do corpo, a cada volta se aproximando do tronco da atleta.

Figura 11 - Na subdivisão $\boldsymbol{e}$, sequências gerando a coleção hexatónica.

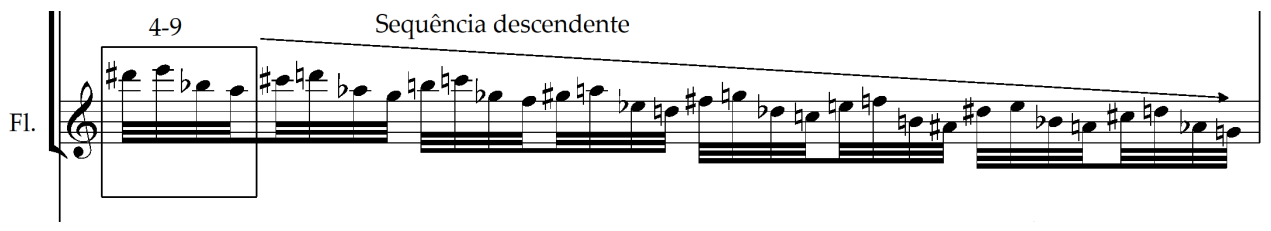

Fonte: Pascoal, Série de arco, comp. 13-14, com intervenção analítica do autor do presente trabalho. 
Nos compassos 15 a 17 (Fig. 12) ocorre um interessante contorno, bastante intenso. Inicialmente, as ondulações geradas pelo movimento contrário das vozes condutoras sugerem gestos circulares na coreografia. Posteriormente, vários movimentos ascendentes com curvas e oscilações remetem a fotografias ou a um olhar seccionado de uma parte do arco quando está girando.

Figura 12 - Na subdivisão $\boldsymbol{e}$, os movimentos contrários das vozes condutoras cedem espaço para movimentos curvos ascendentes. Pascoal, Série de arco, comp. 15-17.

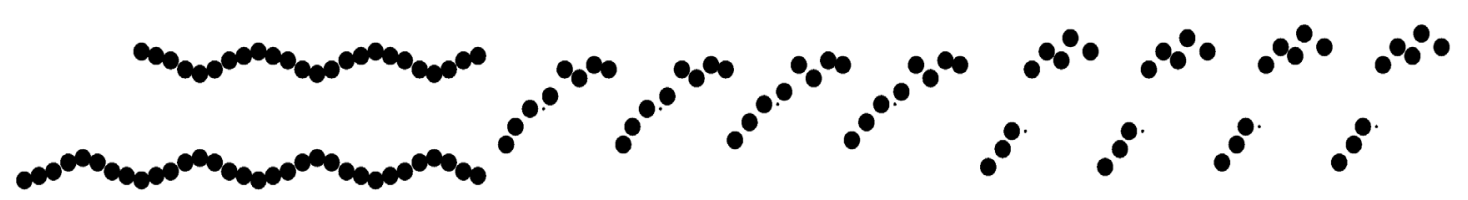

Fonte: Elaborado pelo autor.

Observando os compassos 16 e 17 (Fig. 13), com essa sequência ascendente no qual no arranjo para grupo a flauta realiza uma sobreposição da frase transposta uma terça menor acima (reduzindo as transposições ao âmbito da oitava), percebemos que, no compasso 16, a primeira nota de cada grupo de arpejos encontra-se uma oitava acima em relação ao pentagrama superior do piano. Já no compasso 17, elas estão na mesma oitava. Essa alteração provavelmente adveio da necessidade de adaptação da passagem ao piano para a tessitura da flauta, uma vez que, para que a estratégia anterior fosse mantida, haveriam notas extremamente agudas para a flauta no compasso 17. Todos estes compassos seguem pequenos padrões que são repetidos e transpostos com base na escala de tons inteiros. Por exemplo, o baixo vai sendo transposto em tons inteiros, os arpejos de tríade maior estão em relação de trítono com este baixo, sendo que ambos caminham paralelamente.

Nos compassos 18 e 19 que finalizam essa seção A (Fig. 14), temos um padrão que ocupa dois tempos do compasso composto, formado pela sobreposição de um ostinato arpejando o tricorde 3-8, com blocos de tétrades maiores com sétima maior conduzidos de forma paralela. Na versão para grupo, Hermeto repete mais duas vezes este padrão, totalizando seis repetições e inclui um crescendo de intensidade e densidade com introdução de dobramentos que vai culminar na seção B. 
Figura 13 - Na subdivisão $\boldsymbol{e}$, sequências gerando a coleção hexatónica.

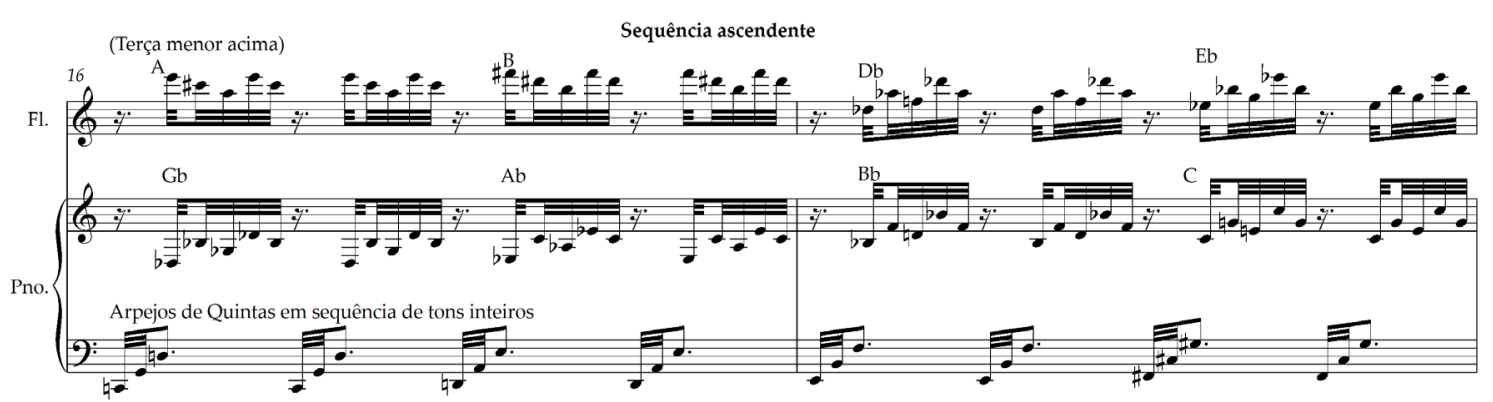

Fonte: Pascoal, Série de arco, comp. 16-17, com intervenção analítica do autor do presente trabalho.

Figura 14 - Na subdivisão $\boldsymbol{e}$, sequências gerando a coleção hexatónica. Na versão para grupo, seis repetições dessa passagem formam uma Ponte.
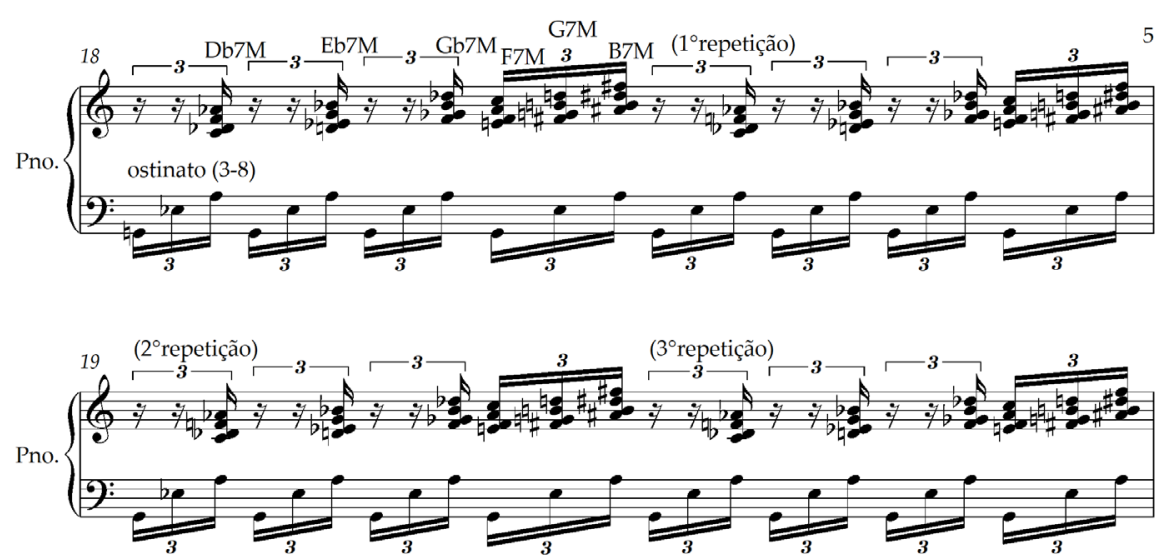

Fonte: Pascoal, Série de arco, comp. 16-17, com intervenção analítica do autor do presente trabalho.

A subdivisão $\boldsymbol{e}$ guarda outra diferença entre a versão original para piano e a versão arranjada para o grupo. Se na versão arranjada, o compasso 20 (Fig. 15) tem a função de ponte, na versão original ele estabelece uma ideia de coda. Originalmente, este compasso não mensurado teria uma breve improvisação em clusters, realizados com a mão aberta percorrendo toda a extensão do piano. Apesar de não estar notado fica subtendido que este seria um gesto em uma intensidade forte e que duraria tempo suficiente para a completude da série com arco pré-determinada, ou seja, poderia ser rápido ou lento de acordo com o tempo que faltasse para completar a coreografia. 
Figura 15 - Compasso sem métrica pré-definida que pode assumir a função de Coda na versão para piano.

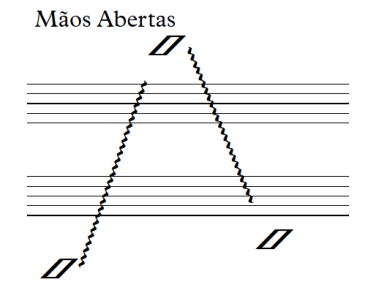

Fonte: Pascoal, Série de arco, comp. 20.

A distribuição das alturas nesta segunda parte da seção $\mathbf{A}$, na parte do piano, é apresentada na Tabela 3:

Tabela 3 - Distribuição das alturas do total cromático nas duas últimas subdivisões da seção A.

\begin{tabular}{lllllllll}
\hline Compassos & Comp. & Comp. & Comp. & Comp. & Comp. & Comp. & Comp. & Comp. \\
& 9 & $10-11$ & 12 & $13-14$ & 15 & 16 & 17 & $18-19$ \\
\hline Qtd. notas & 12 & 12 & 10 & 12 & 6 & 10 & 10 & 12 \\
Notas ausentes & & & C-A & & C-D-E-F\#- & F-B & D\#-A & \\
& & & & & & & & \\
& & & & & & & &
\end{tabular}

Fonte: Elaborado pelo autor.

Na seção B, Hermeto introduz em seu arranjo uma linha melódica para o saxofone. O compasso 21 (Fig. 16) consiste em sobreposições de blocos harmônicos encadeados de maneira livre, formados pela tríade maior com sexta maior ou com sétima maior. Na linha do baixo, temos uma figuração com arpejos do tricorde 3-8, presente na escala de tons inteiros.

Figura 16 - Na seção B, blocos harmônicos sobrepostos a arpejos do tricorde 3-8.

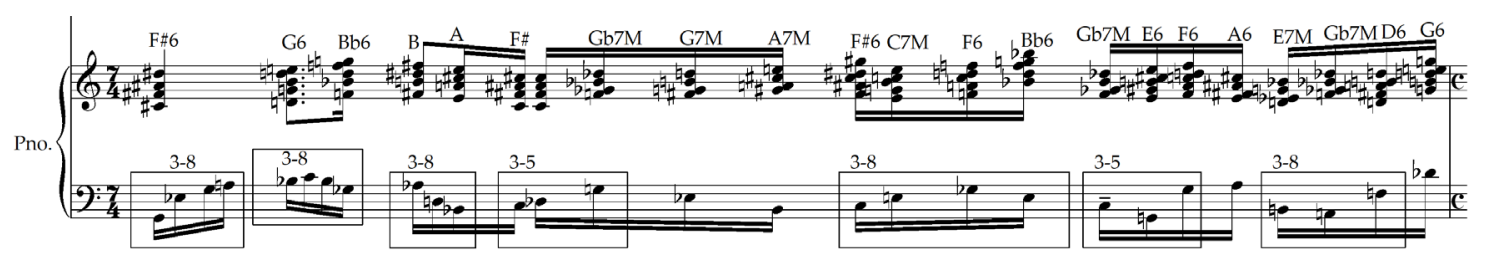

Fonte: Pascoal, Série de arco, comp. 21, com intervenção analítica do autor do presente trabalho. 
A distribuição das alturas na seção B, parte do piano, é apresentada na Tabela 4. Hermeto omite duas alturas do total cromático somente nos dois primeiros compassos; após isto, todos os compassos trazem as doze alturas.:

Tabela 4 - Distribuição das alturas do total cromático na seção B.

\begin{tabular}{lllllllll}
\hline Compassos & Comp. & Comp. & Comp. & Comp. & Comp. & Comp. & Comp. & Comp. \\
& 20 & 21 & 22 & 23 & 24 & 25 & 26 & 27 \\
\hline Qtd. notas & 11 & 11 & 12 & 12 & 12 & 12 & 12 & 12 \\
Notas ausentes & F & G\# & & & & & & \\
\hline
\end{tabular}

Fonte: Elaborado pelo autor.

Na seção B, temos um solo de saxofone soprano, construído sobre a relação entre escala e acorde característica de uma improvisação de jazz. A diferença recai sobre o fato de todo o acompanhamento nos compassos 20 e 21 não seguir essa mesma lógica. Nestes compassos, temos a polarização na tríade de Sol menor tendo a maior parte dos apoios (notas longas e alvo) em notas deste acorde (Fig. 17). Todo o resto funciona como ornamentações do arpejo deste acorde com utilização de bordaduras e arabescos diversos.

Figura 17 - Na seção B, polarização na tríade de Sol menor.

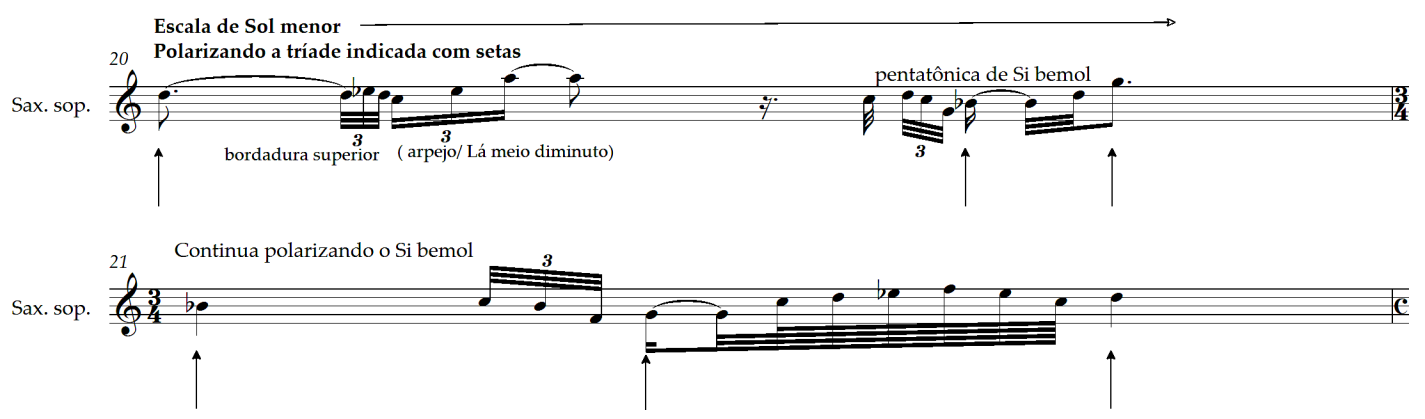

Fonte: Pascoal, Série de arco, comp. 20-21, com intervenção analítica do autor do presente trabalho.

Este solo segue com construção de floreios sobre acordes (Fig. 18), tendo no compasso 22 e 23 um acorde de Mib menor com sexta que acaba gerando a escala de mi 
bemol dórico. No compasso 24 começa um interessante processo cromático, partindo de Dó\# até atingir um Si natural no final do compasso 27. Nesta sequência, temos a relação de Dó menor sendo polarizada nos compassos 25 e 26, chegando ao Si maior no compasso 27. Intercalando essas polarizações, ocorrem pequenos floreios, que funcionam como passagem cromática ou de sensível. No trecho em Dó menor, temos um segmento em Si menor e no trecho em Si maior temos a aparição do arpejo de Sib maior. Este movimento cromático descendente é evidenciado pelo piano, no compasso final da seção.

Figura 18 - Configuração harmônica da seção B.
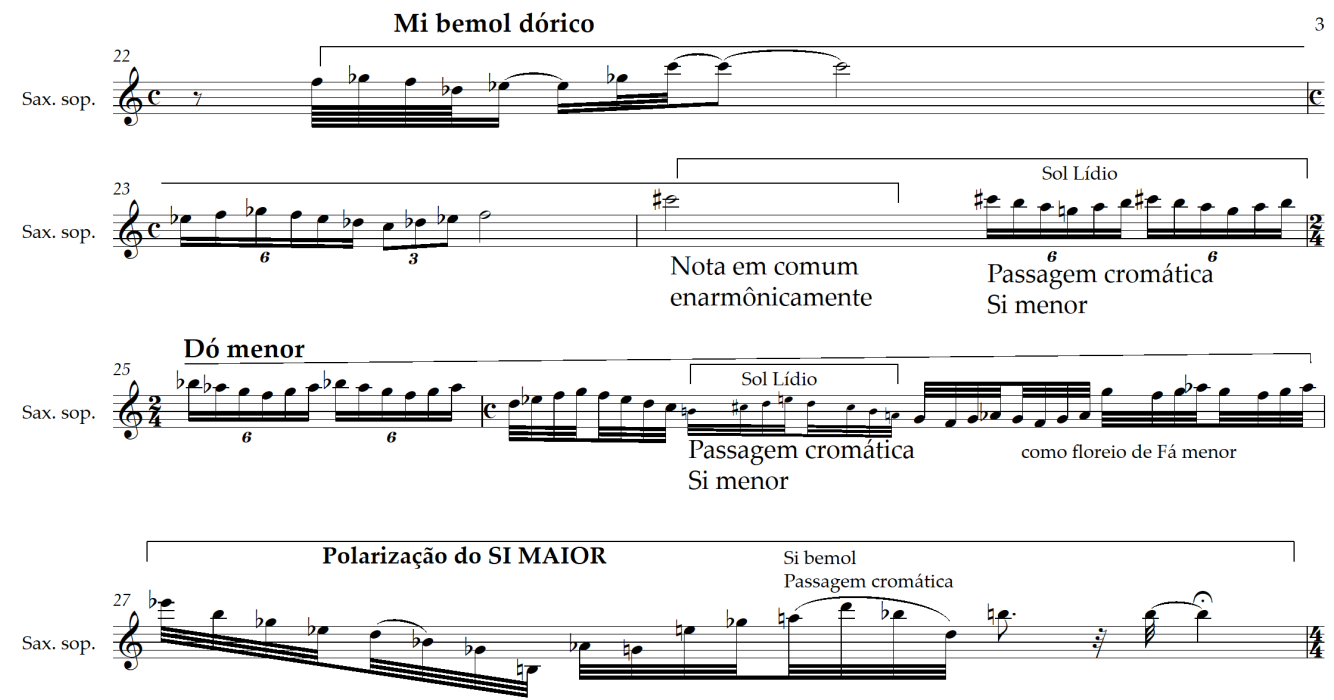

Fonte: Pascoal, Série de arco, comp. 22-27, com intervenção analítica do autor do presente trabalho.

No compasso 27 (Fig. 19), temos uma sequência de sétimas menores descendentes cromáticas que, analisadas em blocos, formam o tetracorde cromático 4-1.

Figura 19 - Configuração harmônica da seção B.

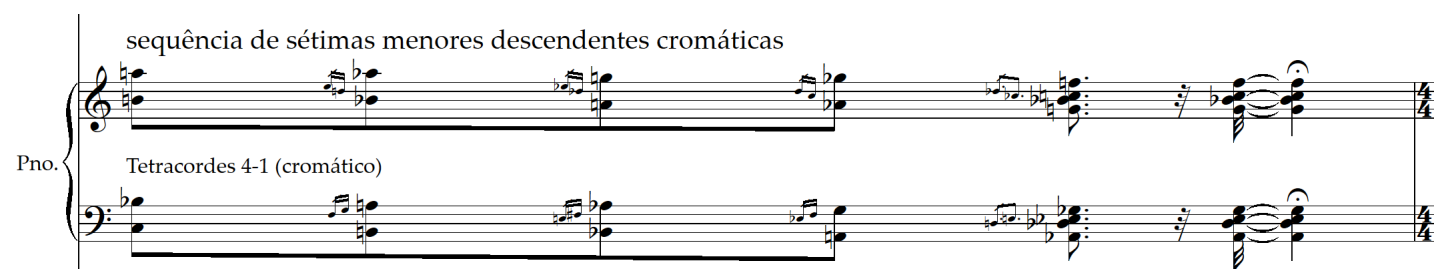

Fonte: Pascoal, Série de arco, comp. 27, com intervenção analítica do autor do presente trabalho. 
Toda a seção B poderia ser reduzida tendo como voz condutora o solo do sax no movimento harmônico: Sol menor (comp. 20-21); Mib menor (comp. 22-24); Dó menor (comp. 25-26); Si maior (comp. 27). Recordando que a seção A' vai repetir toda a primeira seção e seu início se dá na polarização de um acorde de Láb maior (comp. 1 e 28), o qual repousa em um Sol menor (comp. 2 e 29). Inclusive a nota alvo do fim do solo de sax, um Si natural, é resolvida na nota Dó no compasso 29. Em nossa interpretação, o solo de sax da seção B faz este grande movimento através de mediantes cromáticas descendentes que direcionam para a seção A', ou seja, o caráter de Ponte indicado pelo compositor fica mais evidente neste solo composto posteriormente do que na primeira versão de piano solo.

Observando toda a obra do ponto de vista de distribuição do total cromático obtemos a seguinte estatística (Tab. 5):

\begin{tabular}{|c|c|}
\hline Quantidade de compassos & Quantidade de alturas \\
\hline 32 & 12 \\
\hline 4 & 11 \\
\hline 8 & 10 \\
\hline 2 & 9 \\
\hline 1 & 6 \\
\hline
\end{tabular}

Fonte: Elaborado pelo autor.

A despeito desta alta utilização do total cromático, existem sempre polarizações sobre notas ou acordes normalmente reiteradas pela linha mais grave ou utilizada como centro para a construção de escalas. Seguindo essa lógica, podemos obter uma redução (Fig. 20) demonstrando os principais caminhos harmônicos aqui expressos, com ligaduras ressaltando o movimento "cadencial", as setas indicando os pontos de polarização e colocando entre parênteses o número dos compassos equivalentes. 
Figura 20 - Polarizações ao longo da composição. Pascoal, Série de arco, comp. 15-17.

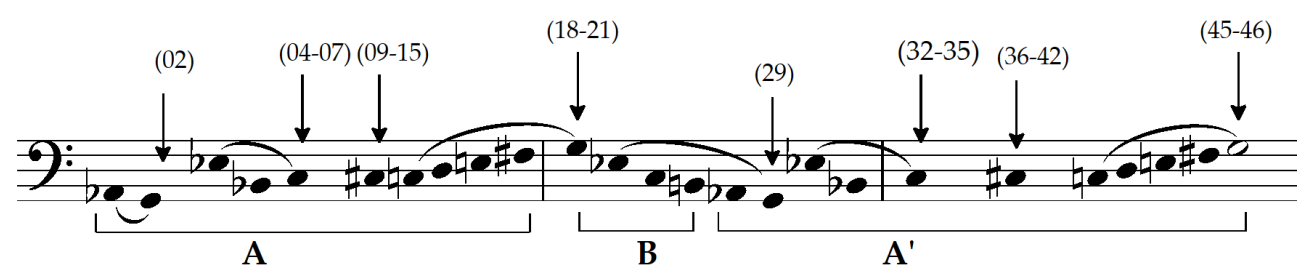

Fonte: Elaborado pelo autor.

Através da observação desta redução (Fig. 20), é possível interpretar que esta composição polariza a nota Sol, descrevendo um caminho que atinge esse centro passando pela tradicional subdominante e contando com o trítono que retorna ao Sol via escala de tons inteiros e mediantes cromáticas. Por isto, apesar de não ser tonal ou modal, esta composição tem polarizações constantes, direcionamentos obtidos principalmente via escala de tons inteiros e repetições - tanto de pequenos padrões quanto de seções completas. Cada fragmento, normalmente organizado em um ou dois compassos, forma pequenos blocos com características singulares que polarizam uma determinada nota ou acorde. Estes, por sua vez, são encaixados e manipulados de forma direcional, estabelecendo uma espécie de cadência que, neste caso, retorna à nota polarizada no primeiro bloco, como um arco.

\section{Considerações finais}

Hermeto realiza a associação entre a coreografia e a música utilizando como processos composicionais principais: recursos de contorno, como movimento contrário e direcionalidade, principalmente ascendente que pode indicar as rotações do arco; sequências de pequenos padrões que são repetidos como movimentos coreográficos semelhantes ou idênticos; processos rítmicos como dilatação e sincopas para indicar a velocidade do movimento ou a utilização de um salto; quase nenhuma utilização de silêncio ou pausas, o que indica uma fluidez ou continuidade dos movimentos; poliacordes, que pode simbolizar a união entre a ginasta e seu instrumento (arco); clusters em momentos mais densos e complexos da coreografia; delimitação contrastante das seções para um entendimento imediato da ginasta. 
Apesar desta obra ser excepcional na produção de Hermeto, por não apresentar uma estrutura de leadsheet, nem seções de improvisação idiomática e tampouco um ritmo popular claramente delineado, acreditamos que esta composição de Hermeto possua uma série de elementos característicos do estilo composicional desenvolvido ao longo de sua experiência criativa. Arriscamo-nos a dizer que grande parte das obras de Hermeto possua relações entre imagem e som. É como se cada elemento musical fosse uma imagem e a sequência destas imagens constitui uma composição. Estas sequências de imagens não são conectadas ao ponto de serem compreendidas como algo contínuo, conforme ocorre no cinema tradicional. Estes encadeamentos de imagens são segmentados e contrastantes, o que individualmente contribui com a identificação destas. Apesar disto, existe um movimento direcional no qual são priorizadas breves repetições, com o intuito de fixar determinada combinação de imagens. No caso específico desta composição, é como se cada imagem consistisse em uma fotografia sonora de um movimento da ginástica rítmica. A reorganização das imagens e suas eventuais modificações geram outras composições, ou seja, não existe inicialmente a necessidade de se criar algo exclusivo para determinada composição. Por isto, propomos que Hermeto seja entendido como um artista bricoleur,

um tipo de produtor que se define pela maneira incorporativa de realizar suas operações, utilizando sempre os instrumentos já disponíveis, ao contrário do engenheiro, que subordina cada tarefa específica "à obtenção de matérias-primas e de utensílios concebidos e procurados na medida do seu projeto" (LÉVI-STRAUSS, 1989, p. 33 apud NAVES, 2000, p. 36).

A maestria artesanal se dá no acúmulo de elementos e sua adaptação a diferentes sequências ${ }^{6}$. Com base na análise da obra Serie de arco, podemos elencar algumas destas estratégias composicionais características do compositor: repetições de pequenos padrões circulares e simétricos estruturados em poucos compassos e construídos sobre arpejos; poliacordes triádicos trabalhados de forma paralela, sequencial e direcional; fragmentos melódicos baseados em escala mixolídia com quarta aumentada, normalmente arpejando o acorde de dominante com pequenas ornamentações; utilização do total cromático em

\footnotetext{
${ }^{6}$ Este processo de bricolagem fica evidente na publicação Calendário do Som (PASCOAL, 2000) com 366 composições escritas entre 1996 e 1997.
} 
um curto espaço de tempo, porém sempre com polarizações e muitas vezes seguindo a escala de tons inteiros; sobreposições de melodias em terças paralelas.

\section{Referências}

BERRY, Wallace. Structural Functions in Music. New York: Dover, 1987.

CABRAL, Thiago; GUIGUE, Didier. (In)Harmonicidade das estruturas verticais na Sinfonia em Quadrinhos de Hermeto Pascoal. In: CONGRESSO DA ASSOCIAÇÃO NACIONAL DE PESQUISA E PÓS-GRADUAÇÃO EM MÚSICA, 27., 2017, Campinas. Anais... Campinas, Universidade Estadual de Campinas, 2019, [s.n.].

COSTA-LIMA NETO, Luiz. A música experimental de Hermeto Pascoal e Grupo (1981-1993): concepção e linguagem. Dissertação (Mestrado em Música) - Universidade do Rio de Janeiro, Rio de Janeiro, 1999.

KOSTKA, Stefan; SANTA, Mathew. Materials and Techniques of Post-Tonal Music. 5 ed. NY: Routledge, 2018.

LEBRE, Eunice M. Xavier Guedes. Estudo comparativo das exigências técnicas e morfofuncionais em ginástica rítmica desportiva. Tese (Doutorado em Ciência do Desporto) Universidade do Porto, Portugal, 1993.

NAVES, Santuza Cambraia. Da Bossa Nova à Tropicalia: contenção e excesso na música popular. Revista brasileira de Ciências Sociais, v. 15, n. 43, p. 35-33, 2000.

PASCOAL, Hermeto. Série de Arco. Partitura manuscrita presente no encarte do LP. Gravadora Som da Gente, SDG 010/92, 1982.

PASCOAL, Hermeto. Hermeto Pascoal \& Grupo. SDG 010/92. São Paulo: Som da Gente, 1982. $1 \mathrm{LP}$.

PASCOAL, Hermeto. Calendário do Som. São Paulo: Editora Senac-Itaú Cultural, 2000.

PERSICHETTI, Vincent. Twentieth-Century Harmony: Creative Aspects and Practice. New York: W. W. Norton \& Company, 1961.

SANTOS, Carlos R. F. Uma investigação sobre os processos composicionais de Arrigo Barnabé no álbum "Gigante Negão". Dissertação (Mestrado em Música) - Instituto de Artes, Universidade Estadual de Campinas, Campinas, 2018.

SANTOS, Carlos R. F. Uma perspectiva de análise sobre a primeira seção da composição "série de arco" de Hermeto Pascoal. In: ENCONTRO INTERNACIONAL DE TEORIA E ANÁlISE MUSICAL, 5., 2019, Campinas. Anais... Campinas, Universidade Estadual de Campinas, 2019, p. 291-303. Disponível em: https://eitam5.nics.unicamp.br/wpcontent/uploads/2020/12/EITAM5-paper_21_SantosC-pp_291-303.pdf. Acesso em: 27 maio 2021.

SANTOS NETO, Jovino. Hermeto Pascoal \& Grupo raridade = Série de arco. Depoimento. Disponível em: https://www.youtube.com/watch?v=meZyeaaB9BM. Acesso em: 27 maio 2021. 
SARÔA, Giovanna R. A História da Ginástica Rítmica em Campinas. Dissertação (Mestrado em Pedagogia do Movimento) - Faculdade de Educação Física, Universidade Estadual de Campinas, Campinas, 2005.

SILVA, Camila Perez. A sonoridade híbrida de Hermeto Pascoal e a Indústria Cultural. Dissertação (Mestrado em Sociologia) - Universidade Federal de São Carlos, São Carlos, 2009.

STRAUS, Joseph N. Introdução a Teoria Pós-tonal. Tradução: Ricardo Mazzini Bordini. Salvador e São Paulo: EDUFBA e Editora UNESP, 2013. 